\title{
A review of motivations, methods, and achievements on microgravity combustion research
}

\author{
Shihong $\mathrm{Ye}^{1}$, Miaomiao $\mathrm{Hao}^{2}$, Haoran $\mathrm{Guo}^{3}$, Lin $\mathrm{Lu}^{4}$, Huanhuan $\mathrm{Xu}^{5,}{ }^{,}$, and Xiaohan $\mathrm{Ren}^{1}$ \\ ${ }^{1}$ Institute of Thermal Science and Technology, Shandong University, Jinan, Shandong Province, \\ China \\ ${ }^{2}$ Center for Ecology and Environmental Protection Education and Communications of Shandong \\ Province \\ ${ }^{3}$ Xi'an TPRI Boiler \& Environmental Protection Engineering Co., Ltd, Xi'an, Shanxi Province, China \\ ${ }^{4}$ ENGIE (China) Energy Technology Co., Ltd., Beijing, China \\ ${ }^{5}$ School of Energy and Power Engineering, Shandong University, Jinan, Shandong Province, China
}

\begin{abstract}
Microgravity combustion has always been one of the key and frontier research fields in the international combustion community. Why has microgravity combustion attracted so much attention? First of all, fire safety and combustion reliability are imminent to spacecraft. Secondly, the convection effect is weakened in the microgravity environment, and the basic combustion phenomena are more prominent, which is greatly helpful to study the fundamental laws of combustion and develop reliable combustion models for fuels. This article systematically summarized and analyzed the research focuses, namely fire safety of spacecraft, droplet combustion, soot formation and flame structures, and current research status in the field of microgravity combustion during the past decades of years. In this paper, motivations, methods, and achievements of fire safety in spacecraft and fundamental combustion characteristics in microgravity were analyzed, which provide a comprehensive review for the microgravity combustion research. Suggestions for the development direction of microgravity combustion science were also made. Improving the application of efficient and clean combustion and optimizing fire safety strategies of new generation spacecraft materials should still be regarded as two critical targets in the future.
\end{abstract}

Keywords: Microgravity combustion; Spacecraft fire safety; Droplet combustion; Soot formation.

\section{Introduction}

The study of microgravity combustion could be traced back to the investigation of microgravity droplet combustion in a simple drop tower in 1957 by Kumagai et al. [1]. After the mid-1980s, ground-based microgravity combustion experiment facilities had been developed [2]. The launch of some recoverable satellites allowed longer and more effective microgravity conditions than drop towers. With the establishment of the space station, such as the ISS (International Space Station) which was built in 2010, the level of microgravity

* Corresponding author: xuhuanhuan@sdu.edu.cn 
experiments has been greatly improved, bringing the study of microgravity combustion entering a new stage.

The studies of combustion in microgravity conditions can be generally carried out experimentally and numerically. Most combustion experiments in microgravity were taken using drop towers. Drop tower is relatively low-cost, but it can only provide a microgravity environment in $1 \sim 10 \mathrm{~s}$. In order to obtain a longer experiment time, experiments can be carried out on a parabolic plane $\left(20 \mathrm{~s}, 10^{-2} \mathrm{~g}\right)$, sounding rocket $\left(5 \sim 10 \mathrm{~min}, 10^{-4} \mathrm{~g}\right)$, and space vehicle (days, $10^{-5} \sim 10^{-6} \mathrm{~g}$ ) [3]. The complexity and high cost of experiments in microgravity environment drove researchers to develop some calculation models in microgravity. However, to pursue high computational efficiency, combustion simulation models need to be simplified, and the reliability of the calculation results should be verified by some reported experimental results.

It is complicated and high-demand to create a microgravity environment on earth; besides, although space stations can provide long-term continuous microgravity conditions, these facilities are extremely expensive. So why did many countries in the world invest countless money and manpower to study combustion in microgravity? This paper introduced the intents of the scientists and the efforts they have made in studying microgravity combustion. To gain a thorough insight into the proposes, methods and achievements of microgravity combustion, investigations on the fire safety of spacecraft, development of droplet and combustion theory were reviewed and summarized, and suggestions for the future research of microgravity combustion were also made.

\section{Motivation and achievements of microgravity combustion research}

\subsection{Improvement on the fire safety of spacecraft}

Fire safety is an important issue that must be solved appropriately during the design and operation of manned spacecraft. Since the 1960s, great emphases from many major aerospace powers have been put on the combustion characteristics of materials in a microgravity environment. It is well known that most fires are caused by current overload and wire short circuit, then spread through the wire insulation. So, it is critical to investigate the burning characteristics of wire insulation materials for spacecraft fires prevention. Nagachi et al. [4] experimentally studied the spread of concurrent flames on wire insulation in microgravity conditions provided by parabolic flights. They found that the flame propagate rate increased with the external flow velocity, and the stable propagate rate of copper wires is faster than that of nickel-chrome wires. He et al. [5] experimentally examined the flame propagation and dripping characteristics on wire insulation under overload currents. Results showed that the mean drip rate of the molten insulating layer is proportional to the square of the current. Another type of fire occurred in a spacecraft is that fire burns on a solid surface. Olson et al. Shih and T'ien [6] theoretically and numerically investigated a three-dimensional, stable, laminar flame propagation model on thin solids in low-velocity concurrent flow. They found that a wider solid has a higher flame propagation speed than other samples.

\subsection{Development of droplet combustion}

Spray combustion is utilized in almost all the liquid-fueled combustion chambers, such as jet engines and diesel engines. The research about droplet characteristics, such as flame propagation in droplet array and droplet combustion in high pressure, benefits the analysis 
of the fundamental phenomena of spray combustion. In order to gain insights into the combustion process of liquid fuel in power and propulsion devices and improve the performance of practical burners, many scientists were interested in the research of microgravity droplets. Mikami et al. [7] and Kikuchi et al. [8] studied the n-decane droplet array at high temperatures through experiments and simulations, respectively. They found that the ambient temperature influences the flame propagation mode and flame propagation speed, and the flame propagation speed positively correlates with ambient temperature. Mikami et al. [9] experimentally studied the flame propagation characteristics of fuel droplet cloud element with uneven droplet spacing in microgravity conditions. Considering the temperature distribution development, they discussed the flame propagation after the two droplets interacting in different directions, presented an approximate value of the limit distance of flame propagation. Kobayashi et al. [10] experimentally investigated the flame propagation characteristics of n-decane droplet array within the supercritical pressure range in microgravity. They found that as the pressure increases, the propagating speed of flame in microgravity decreases first, then increases, and then decreases. It reaches the minimum near half of the critical pressure, and reaches the maximum near the critical pressure.

\subsection{Development of combustion theory}

\subsubsection{Soot formation}

Carbon deposits may cause poor operation reliability of a combustion equipment. The existence of soot in flame has noticeable impacts on heat transfer, especially on radiant heat loss. Besides, soot formation brings challenges to the modeling of droplet dynamics. Therefore, in-depth exploration of soot generation and oxidation mechanism during the combustion process is of great significance for improving combustion equipment as well as the modeling of droplet dynamics. Recently, Guibaud et al. [11] developed embedded optical techniques to explore the radiant heat feedback related to soot in flame propagation in microgravity. Kong and Liu [12-13] numerically studied the effect of gravity on soot formation characteristics by simulating a laminar methane/air diffusion flame. The results showed that changing gravity alters the location and intensity of soot nucleation and surface growth. Jeon et al. [14] conducted experiments with a coaxial flow of $0-7.2 \mathrm{~cm} / \mathrm{s}$ in microgravity, and results showed that the soot concentration is positively correlated with the external coaxial flow rate. Ma Et al. [15] built up a series of comprehensive and novel coaxial diffusion flame data in microgravity, including soot characteristics of $\mathrm{CH}_{4}$ coflow jet flames in different gravity conditions. The result showed that the flame has a lower temperature and a higher soot concentration in microgravity when compared with combustion in normal gravity.

\subsubsection{Flame structures}

Increasing combustion efficiency and decreasing pollutant emission are the key pursuits in the current combustion engineering. Achieving this important goal must be based on a thorough understanding of combustion's basic laws and characteristics. The microgravity environment provides not only great conveniences for the research of fundamental combustion, but also high possibilities in solving many academic arguments in normal gravity. Therefore, significant efforts have been made to study flame structures in microgravity. The study of laminar diffusion flames lays a solid foundation for understanding more complex combustion such as turbulent flames. Aalburg et al. [16] studied the flame shape of a circular laminar jet diffusion flame in zero gravity conditions. They found that, for the same fuel and oxidizer, the length of flame-sheet increases with the 
increase in fuel mass flow velocity, and regardless of the burner diameter. Cao et al. [17] computationally and experimentally investigated the influence of fuel dilution, inlet velocity, and gravity on flame characteristics. Their works showed that the mass flow velocity of fuel dominates both the buoyant and nonbuoyant flame structures, followed by the fuel dilution and inlet velocity. Charest et al. [18] used numerical methods to explore the effects of pressure and gravity on coflow ethylene/air laminar diffusion flames. Results showed that the same flame shows different correlations between pressure and flame shape in normal gravity and zero-gravity conditions.

\section{Conclusions and suggestions}

Deepening the understanding of the combustion process and enhancing the handling of manned spacecraft fire safety issues are still two main goals during the study of combustion research in microgravity. Researches of microgravity combustion significantly contribute to a comprehensive and in-depth understanding of combustion mechanisms and characteristics. In microgravity conditions, natural convection is remarkably weakened or even eliminated, and the residence time of combustion products will be prolonged. All these changes benefit studying static and low-velocity combustion. In such combustion processes, many phenomena are concealed by buoyancy and its induced effects.

This paper summarized the key issues and current research status in the field of microgravity combustion during the past decades of years. Motivations, methods, and achievements of fire safety in spacecraft and fundamental combustion characteristics in microgravity were analyzed. Based on the thorough review, suggestions for the development direction of microgravity combustion science were made as follows: Firstly, the basic scientific research on microgravity combustion is still quite essential for the more profound understanding of the dynamic mechanism of the combustion process, which lays a solid foundation for the design of efficient and clean engines; Secondly, for the sake of the importance of fire safety in spacecraft, the flammability and flame propagation characteristics of materials should continue to be researched, and more efforts need to be made on the development of fire detectors and novel efficient fire extinguishing agents.

\section{Acknowledgement}

This work was financed by Shandong Provincial Natural Science Foundation of China (Grant No. ZR2020QE198), China Postdoctoral Science Foundation (Grant No. 2020M672059), and the Fundamental Research Funds of Shandong University.

\section{References}

1. Kumagai, S., and Isoda, H. (1957). Combustion of fuel droplets in a falling chamber. Symposium (International) on Combustion, 6(1), 726-731.

2. Friedman, R. and Ruff, G. A. (2003). Spacecraft Fire Safety 1956 to 1999. ntrs.nasa.gov.

3. Zhang, X. (2004). Research advances on microgravity combustion. Adv Mech, 34 ( 4 ), 507-528.

4. Nagachi, M., Mitsui, F., Citerne, J. M., Dutilleul, H., Guibaud, A., Jomaas, G., Fujita, O. (2018). Can a spreading flame over electric wire insulation in concurrent flow achieve steady propagation in microgravity? Proceedings of the Combustion Institute.

5. He, H., Zhang, Q., Tu, R., Zhao, L., Liu, J., \& Zhang, Y. (2016). Molten thermoplastic 
dripping behavior induced by flame spread over wire insulation under overload currents. Journal of Hazardous Materials, 320, 628-634.

6. Shih, H. Y., T'ien, J. (2003). A three-dimensional model of steady flame spread over a thin solid in low-speed concurrent flows. Combustion Theory and Modelling, 7(4), 677-704.

7. Mikami, M., Oyagi, H., Kojima, N., Wakashima, Y., Kikuchi, M., \& Yoda, S. (2006). Microgravity experiments on flame spread along fuel-droplet arrays at high temperatures. Combustion and Flame, 146(3), 391-406.

8. Kikuchi, M., Wakashima, Y., Yoda, S., \& Mikami, M. (2005). Numerical study on flame spread of an n-decane droplet array in different temperature environment under microgravity. Proceedings of the Combustion Institute, 30(2), 2001-2009.

9. Mikami, M., Watari, H., Hitose, T., Seo, T., Saputro, H., Moriue, O., \& Kikuchi, M. (2017). Flame spread of droplet-cloud elements with two-droplet interaction in microgravity. Journal of Thermal Science and Technology, 12(2), JTST0028-JTST0028.

10. Kobayashi, H., Park, J., Iwahashi, T., \& Niioka, T. (2002). Microgravity experiments on flame spread of an n-decanedroplet array in a high-pressure environment. Proceedings of the Combustion Institute, 29(2), 2603-2610.

11. Guibaud, A., Citerne, J.-M., Consalvi, J.-L., Torero, J. L., Fujita, O., Kikuchi, M., Legros, G. (2020). Accessing the soot-related radiative heat feedback in a flame spreading in microgravity: optical designs and associated limitations. Proceedings of the Combustion Institute.

12. Kong, W., \& Liu, F. (2009). Effects of Gravity on Soot Formation in a Coflow Laminar Methane/Air Diffusion Flame. Microgravity Science and Technology, 22(2), 205-214.

13. Kong, W., \& Liu, F. (2009). Numerical study of the effects of gravity on soot formation in laminar coflow methane/air diffusion flames under different air stream velocities. Combustion Theory and Modelling, 13(6), 993-1023.

14. Jeon B.H., Fujita O., Y uji Nakamura Y., \& Ito H. (2007). Effect of Co-Axial Flow Velocity on Soot Formation in a Laminar Jet Diffusion Flame under microgravity. Journal of Thermal Science and Technology,2, 281-290.

15. Ma, B., Cao, S., Giassi, D., Stocker, D. P., Takahashi, F., Bennett, B. A. V., ... Long, M. B. (2015). An experimental and computational study of soot formation in a coflow jet flame under microgravity and normal gravity. Proceedings of the Combustion Institute, 35(1), 839-846.

16. Aalburg, C., Diez, F. J., Faeth, G. M., Sunderland, P. B., Urban, D. L., \& Yuan, Z.-G. (2005). Shapes of nonbuoyant round hydrocarbon-fueled laminar-jet diffusion flames in still air. Combustion and Flame, 142(1-2), 1-16.

17. Cao, S., Ma, B., Bennett, B. A. V., Giassi, D., Stocker, D. P., Takahashi, F., ... Smooke, M. D. (2015). A computational and experimental study of coflow laminar methane/air diffusion flames: Effects of fuel dilution, inlet velocity, and gravity. Proceedings of the Combustion Institute, 35(1), 897-903.

18. Charest, M. R. J., Groth, C. P. T., \& Gülder, Ö. L. (2011). A numerical study on the effects of pressure and gravity in laminar ethylene diffusion flames. Combustion and Flame, 158(10), 1933-1945. 